\title{
ЈCOM \\ Discourse media analysis of risk and responsibility for environmental pollution
}

Book

Reviewed by

Abstract

Keywords

DOI
Hook, G. D., Lester, L., JI, M., Edney, K. And Pope, C. G. (2017).

Environmental Pollution and the Media, Political Discourses of Risk

and RESPONSIBILITY IN AUSTRALIA, ChINA AND JAPAN.

LONDON AND NEW YORK: ROUTLEDGE

\section{Jennifer Metcalfe}

This book examines the media discourses about environmental pollution in Australia, China and Japan. The book's authors focus on the actors involved in discussions of risk versus those involved in responsibility for environmental pollution. The authors use novel and traditional means of analysis that combine techniques from a variety of disciplines to examine case studies of media discourse. The book provides an interesting, if at times simplistic, overview of the pollution issues facing each country. The conclusions made from the media analysis are relevant to those researching and practicing science communication in the context of such important environmental issues.

Environmental communication; Risk communication; Science and media

https://doi.org/10.22323/2.17020702

It is refreshing to read a book on environmental media discourse analysis that it not situated in the context of the United Kingdom, Europe or the United States. Instead, this book examines the nexus between climate change, media discourse and policy within the settings of Australia, China and Japan. Moreover, the various authors bring a mix of disciplines to their analysis: political science, area studies, linguistics, cultural studies and media studies. This diversity of disciplinary backgrounds means the authors used or combined a mix of techniques for analysing media, including data mining tools.

The authors claim to have developed and applied new analytical frameworks "from corpus linguistics and empirical language and cultural studies to enhance transdisciplinary collaboration to tackle research issues of contemporary social significance" (p. 5). Certainly science communication scholars will likely find some of the methods used of interest, particularly those used to analyse the media coverage of pollution issues facing the Great Barrier Reef in Australia, and the media coverage of pollution issues in Japan. However, at times I found it difficult 
to follow the methods and results described. Details about the assumptions being made, for example, are often missing or overlooked.

But, this is not just a book about new methods and transdisciplinary approaches to media analysis. The book provides an interesting overview of some of the big pollution issues facing the governments and societies of Australia, China and Japan. The second chapter of the book provides a regional overview for each country, and gives the reader initial insight into how the issues facing each country are linked, while being very different from each other. Australia's economy is driven by mining and exporting fossil fuels, which leads to inevitable environmental degradation and puts the health of iconic assets like the Great Barrier Reef at risk through increasing climate change as well as the local effects of port development and dredging. Australia's biggest export of coal is to China, where accelerating economic development and large-scale projects are continuing to create a number of environment risks, especially the severe issue of air pollution in its major cities. The advent of the Internet, mobile phones and social media has resulted in a growing public awareness of these risks, and their impacts on human health. China's air pollution is such that it even affects neighbouring countries such as Japan. Japan's own history of pollution is shaped by its drive to catch up with Western industrialisation, which started in the mid 1850s, and meant that development was prioritised over the environment. Between 1967 and 1973, the 'big four' pollution cases were brought to court, and Japanese media helped to showcase the harmful effects of such pollution (e.g. sulphur dioxide emissions) on human health.

No doubt the space for providing more detail on the political, social and cultural contexts of each country was limited. However, at times I found the overview, background and conclusion sections of the case study chapters overly simplistic. For example, in the Australian context, which I obviously know best, the authors made statements that were either inaccurate or only part of the whole story. For example, the book stated that the reason why Australia did not suffer as much as other countries from the Global Financial Crisis was the mining boom. Many political and economic commentators and scholars would also point to the role of government financial incentives and the relative health of our banking system. In another statement, the book claims that Australians follow global trends when it comes to attitudes on climate change. If the authors are talking about trends in the UK or US, then perhaps they are right. But Australian attitudes are very different to those in large parts of Europe, Africa or Latin America [Morrison et al., 2013; Stokes, Wike and Carle, 2015].

However, of more concern to me was the research on Australia's media discourse on the Great Barrier Reef. The corpus analysed included texts from both Murdoch and Fairfax owned media, along with more academic articles from The Conversation. These media texts were not differentiated despite the well-known fact that Murdoch's News Media has a history of reporting that is anti-climate change science and pro development, while the reverse is the case for Fairfax media [Bacon, 2013]. Likewise, when describing political and policy events the differences between Liberal (conservative) or Labor (progressive) governments and policies are not clearly distinguished. While the authors acknowledge their study is not an exhaustive analysis of the media, I would have thought such contexts were important influences on any conclusions made. 
The most interesting chapter for me was the one on China (Chapter 4), which described the documentary, Under the Dome, produced by investigative environmental journalist Chai Jing in 2015. This chapter did not attempt to apply the complicated mix of quantitative and qualitative analysis that the other case studies did. Instead, it used simple qualitative analysis to tell the story of the film's release just prior to a meeting of the National People's Congress. Interestingly, the authors equate activism with investigative journalism although they do not explain this premise. Regardless, this is a fascinating story of how a Chinese journalist is able to release a landmark and critical piece of journalism without putting the government too much offside, at least initially. Chai Jing appeals to the government by using their own language and without direct confrontation in a process the authors refer to as "negotiated symbiosis". In less than a week, her documentary had more than 300 million online views and its impact on Chinese governments and society cannot be underestimated.

The book's focus on looking at whose pollution it is, and who is responsible for the risks and managing those risks is an interesting and important one. The authors' conclusions about how these are reported in the media in each country are relevant to science communication scholars and practitioners. Australia is a country where environmental risks and responsibilities are contested in the media. China's media is still dominated by the relationships journalists have with the state, including government-operated NGOs (or GONGOs). Japan's media discourse is driven by both national and international events with the national government along with scientists driving the discourse about risk, and regional governments and industry driving the discourse about responsibility. This is a discourse that changes over time. While Japan's national government supports dialogue and scientific evidence of pollution risks, it offloads responsibility for dealing with those risks to others, and ultimately it is up to the individual citizen to take responsibility for how they avoid or mitigate such risks.

Considering what the book's findings means for how we communicate about pollution science is important if we want to help tackle the crucial and international issue of increasing pollution and its consequent effects on climate change, human health and our natural environments. Clearly, any communication strategies need to understand local contexts and history, as well as the role of the media in such communication. In Australia, more direct communication with government, industry, community and individual decision makers will help avoid the confusion of an increasingly polarised media landscape. In China, the role of government-trusted journalists who can still perform investigative journalism will be an important consideration. In Japan, it will mean working with regional, industry and individual decision-makers so they have the knowledge they need to be able to make decisions about how they respond to pollution issues. 
Bacon, W. (1st November 2013). 'Big Australian media reject climate science'. The Conversation. URL: https://theconversation.com/big-australian-media-rej ect-climate-science-19727 (visited on 4th February 2018).

Morrison, M., Duncan, R., Sherley, C. and Parton, K. (2013). 'A comparison between attitudes to climate change in Australia and the United States'. Australasian Journal of Environmental Management 20 (2), pp. 87-100. https://doi.org/10.1080/14486563.2012.762946.

Stokes, B., Wike, R. and Carle, J. (5th November 2015). 'Global Concern about Climate Change, Broad Support for Limiting Emissions'. Pew Research Center. URL: http://www . pewglobal org/2015/11/05/global-concern-about-climat e-change-broad-support-for-limiting-emissions/ (visited on 4th February 2018).

Author

Jenni Metcalfe works as a science communication practitioner in Australia and internationally in her own business, Econnect Communication. She is also a Ph.D. scholar at the Australian National University where she is studying the application of science communication theories to practice by looking at examples of climate change communication. E-mail: jenni@econnect.com.au.

\section{How to cite}

Metcalfe, J. (2018). 'Discourse media analysis of risk and responsibility for environmental pollution'. JCOM 17 (02), R02.

https://doi.org/10.22323/2.17020702. 